\title{
The Ethical Experience of Nature: Aristotle and the Roots of Ecological Phenomenology
}

Dylan B. van der Schyff, Simon Fraser University, Canada

Email: dva5@sfu.ca

\section{Abstract}

I demonstrate here how Aristotle's teleological conception of nature has been largely misunderstood in the scientific age and I consider what his view might offer us with regard to the environmental challenges we face in the 21st century. I suggest that in terms of coming to an ethical understanding of the creatures and things that constitute the ecosystem, Aristotle offers a welcome alternative to the rather instrumental conception of the natural world and low estimation of subjective experience our contemporary techno-scientific culture espouses. Among other things, I consider how his conception of orexis and eudaimonia (happiness or, as I prefer here, "the flourishing life") might be extended to include the eco-system itself, thus allowing us to better understand the moral meaning of nature. I conclude with a look at the way in which modern phenomenology re-addresses the fundamental Greek concern with ontology, meaning and human authenticity. I consider the ways in which phenomenology reasserts the value of direct human experience that was so important to Aristotle; and I consider how this view, and that of Deep ecology, may help us to experience nature - and all of Being for that matter - in a more authentic, meaningful and altogether ethical light.

\section{Introduction}

[Phenomenology] is also a philosophy for which the world is always "already there,” before reflection, like an inalienable presence, and in which every effort is made to rediscover a naïve contact with the world.... It is the attempt at a direct description of our experience such as it is ... it is in ourselves that we will find the unity of phenomenology and its true sense. (Merleau-Ponty 1945, p.1-2)

With the publication of Edmund Husserl's last book, The Crisis of the European Sciences, an early chapter was added to a growing critique of the modern conception of science and philosophy. While Husserl clearly recognized the outstanding achievements brought about by the Scientific Revolution, he identified what he considered to be a serious problem regarding the way in which the scientific age had come to view the world in the late 19th century. Husserl 
claimed that the social sciences had become "blinded by the prosperity" produced by the positive sciences and that this had led to a world view that was increasingly determined by technological progress. Husserl saw this as an "indifferent turning away from the questions which are decisive for a genuine humanity” (Husserl, pp. 6-10). In The Crisis, Husserl draws attention to the modern disconnect between our knowledge of how things work and what they mean; he explores the reasons for the exclusion of human questions in modern science; and, finally, seeks to reestablish the human element with the development of a new science, phenomenology, which takes human experience as its basis.

Husserl's phenomenology became influential in the 20th century, most notably in the work of Martin Heidegger and Maurice Merleau-Ponty. And the writings of all three of these thinkers formed the philosophical core for the work of more recent thinkers like Arne Naess, Michael Zimmerman, Ezrahim Kohak and Neil Evernden. In response to the growing divide they saw between human culture and the natural world - now manifest most clearly in the environmental crisis we face - these ecologically-minded thinkers extended phenomenology towards the contemplation of nature and our relationship to it. But many centuries before Husserl, Heidegger, and the beginnings of modern Eco-phenomenology and Deep ecology proper, there was, of course, Aristotle, who put forward what was perhaps the first comprehensive phenomenological view of nature.

There is a very real sense in which Husserl and the thinkers that followed him sought to reintroduce a way of seeing the world that Aristotle and the Greek philosophers embraced many centuries before - one that was lost, or at least rejected and repressed in the Scientific Age. Indeed, the very conception of science and philosophy that Husserl critiques in The Crisis emerges from the same world-view that claims that the modern scientific project could not get started until the authority of Aristotle was overturned. ${ }^{1}$ But, as I'll discuss shortly, this "authority of Aristotle" was based on a kind of Christianized Aristotelianism that Aristotle himself would have rejected almost completely.

Just as Aristotle's view of nature embraces a distinctly natural human perspective, so too is the primary goal of phenomenology to reveal the world as it is given to consciousness - as distinct from (or antecedent to) any cultural, scientific, historic, or psychological assumptions we may have formed of it. Put more simply, phenomenology strives to know the world as it is perceived by the "naked eye" and as it is experienced by the open mind. And while there is indeed much in Aristotle's account of nature that invites criticism, it is nonetheless a wonderful example of the kind of meaningful view of the world it is possible to arrive at from precisely this first person perspective. It is with this in mind that I would like to examine Aristotle's view of nature and consider the relevance it may have for us in the 21st century. First, I will look at the teleological account of nature that Aristotle presents in his Physics (and which emerges throughout his corpus). Here I will examine how Aristotle's method differs from the modern inquiry into natural phenomena - especially with regard to its affirmation of direct human experience or "appearances" - and consider how Aristotle's view of the world may help us to understand natural beings, ourselves included, as intrinsically purposeful entities. Then, in light of the concept of eudaimonia found in Aristotle's Nicomachean Ethics, I will suggest that we may be able to propose a simple but strong argument for natural purpose as a universal ethical truth. To conclude, I will briefly consider the more recent philosophical discourse that attempts to reassert direct human experience as a valid vantage point from which we may know the world; and I will consider how this perspective bears on recent philosophical positions (like Ecophenomenology and Deep Ecology) that seek to understand nature in ethical terms. All along I 
hope to make it clear that while both the ancient and modern phenomenological perspectives cannot replace our contemporary techno-scientific culture, it may nonetheless allow us to rediscover a fundamental and altogether natural way of seeing the world that has been largely ignored or otherwise rejected in the modern age. I will further suggest that this perspective may be able to become integrated with our current techno-scientific view of the world; that it may be applied practically in terms of public policy making; and that it may allow us, finally, to recognize and integrate the natural ethos that many of us are searching for so desperately.

In order to confront the environmental crisis we face we are going to have to look as deeply into ourselves as we do into the world that surrounds us and gives us life. As Evernden points out, we must begin "with the recognition that the source of the environmental crisis lies not without but within, not in industrial effluent but in assumptions so casually held as to be virtually invisible” (Evernden, 1993, p.xii). Indeed, much of our understanding of nature, culture and who we are comes from ideas handed down to us from the grand narratives of modern culture, where science and technological progress reign supreme - and where personal experience is often denounced as "merely subjective." But this perspective is showing itself to be increasingly inapposite to the flourishing of life on our planet; we can no longer live solely through the constructs of our own artifice. As a culture and as individuals, we are being called upon to assume a new phenomenological responsibility - one that re-embraces the most natural and primordial way in which we know the world. Above all, I hope to show here that if our goal is to discover an ethical experience of nature, then both the ancient writings of Aristotle and the modern insights of phenomenology are particularly well-suited to the task.

\section{Theoria: Aristotle's “Seeing” of Nature}

All men by nature desire to know. An indication of this is the delight we take in our senses; for even apart from their usefulness they are loved for themselves; and above all others the sense of sight.... science and art come to men through experience. (Aristotle, Metaphysics I. 980a-981a)

Aristotle's interests were famously diverse. He wrote extensive works on logic, ethics, physics, metaphysics, biology, astronomy, meteorology, mathematics, psychology, zoology, rhetoric, aesthetics, and politics; he and his students collected and studied manuscripts, maps, zoological samples, botanical samples, and political constitutions. The influence of Aristotle and his Lyceum on the Western world is enormous and his ideas greatly influenced the development of the European university and Western civilization itself. But as far reaching as Aristotle's influence on Western intellectual history is, it is also important to consider his relationship to the tradition of Greek philosophy and science that came before him. Indeed, Aristotle's work is often considered to be the dialectical peak of the great tradition of Hellenic and Hellenistic investigations into the natural world that began with Thales. This is to say that Aristotle's work is in no way a departure from those great thinkers that preceded him, but rather it represents a great gathering and rethinking of the whole tradition of Greek thought.

Indeed, Aristotle engages in the centuries-long dialogue that is Greek philosophy on a level that is unmatched both in terms of its depth and comprehensiveness. But while it is not unusual for us to think of the Ancient Greeks in terms of their great influence on the Western philosophical tradition, their contribution to our scientific tradition is often given too little credit 
in the modern world. Part of the reason for this has to do with a certain prejudice surrounding the belief that Greek science had to be overturned so that the modern scientific project could get underway - I'm referring to this "authority of Aristotle" I mentioned earlier. But while the Christianized version of Aristotelian thought would indeed have a kind of suffocating effect on scholarship that the thinkers of the 17th century successfully challenged, Aristotle's proper conception of science was far more vibrant and rigorous than the absolute and unchanging version of it that was imposed by the Church. One phrase that shows up again and again in Aristotle's scientific writings speaks to this: namely, hôs epi to polu, which can be translated as “for the most part”, "by and large”, or, “in general” (Phys II. 8, 198b34).

Aristotle understands that when it comes to the facts of the world as they are perceived, the best one can do is to try to work out a systematic understanding of things and attempt to subsume them under general laws. However, for Aristotle, knowledge of a given subject can only be achieved insomuch as the subject will allow; and indeed, some subjects will allow far greater scientific precision than others. Thus the best we can say - in Aristotelian terms at least - is that, with regards to subject $\mathrm{X}, \mathrm{Y}$ is the case either always or for the most part (hôs epi to polu). And if a better or more accurate account of the subject can be arrived at from another perspective, then so much the better for science and philosophy. Indeed, Aristotle recognizes that proper scientific inquiry must be subject to corrigibility. ${ }^{2}$ He understands that scientific statements are not pronouncements, but rather statements of fact that are always subject to further inquiry and refinement by some other account. However, the interpretation of Aristotelian thought that would become so central to the teachings of the Church could not allow for the possibility of this kind of corrigibility - such an acknowledgement would have undermined the eternal and unchanging image of the cosmos that was so instrumental in supporting the absolute authority of the Church. As a result, Aristotelian thought was reduced to a set of unchanging precepts; and it was this static Christian interpretation of Aristotle's works that 17th century thinkers like Galileo successfully overturned, not Aristotle's thought proper. As I will discuss in more detail, Aristotle's view of nature relies heavily on the evident appearances and/or facts of perception (the phainomena ${ }^{3}$ ) - it is not made to fit some preordained religious, political, or economic view of how the world should be. And so, while there is a great deal more that could be said about Aristotle's relationship to Western science in general, for our purposes it will be enough to keep in mind that he is, above all else, a "theoretical philosopher" in the Classical Greek sense of the term - where theoria literally means "looking at."

In the Metaphysics, Aristotle writes that of all the senses available to us, human beings prefer sight. The reason, he claims, is that it is sight above all else that gives us knowledge of things. However, for Aristotle, "sight" is not only a source of knowledge, it also signifies a process of understanding purpose, meaning, and value: an Aristotelian theoretical treatise is a report on what is "seen" both physically and in terms of human insight. In this way Aristotle's entire body of work can be thought of as an attempt to "see" the world as it really is-from the plants, animals, and human society that surround us, to the starry heavens above. For Aristotle, the way things appear is, hôs epi to polu, a fundamental clue to the way things really are.

Unlike the Platonic dialectic that continually seeks to refine the question, Aristotle's theoria searches for answers. Like Plato, however, Aristotle fiercely opposes sophistic relativism; he has great confidence in the human ability to know the world in an objective sense. And thus when Aristotle writes, "all human beings by nature desire to know," he is placing inquiry, knowledge and reason themselves well within the realm of nature as objective and altogether natural human characteristics. Furthermore, for Aristotle it is not enough to know the material causes of things; 
one must also strive to know the purpose and meaning towards and because which they tend to move - an epistemic consideration from which modern science clearly tends to retreat. Indeed, there is a strong ethical dimension to Aristotle's theoria that can only be fully appreciated through the first-hand experience of nature (phusis) as a series of interrelated and intrinsically meaningful phainomena. So while it is indisputable that modern science is able to observe and make highly accurate claims about the physical world in a way that Aristotle could scarcely have imagined, there is a very strong sense in which Aristotle has a far better grasp on what it means to be a human being who exists in nature and who sees the world through the "naked eye." Indeed, for Aristotle, the very point of studying nature was not merely to understand how things worked or what they were made out of, but rather to grasp the purpose of things, or their telos. And he had great confidence that the natural world was knowable in this way because he believed that the human mind was capable of perceiving and understanding beauty and form not only in an aesthetic sense, but as part of an innate moral faculty as well.

\section{Form and the Principle of Movement}

As we have just considered, Aristotle embraces empirical experience as the primary source of knowledge. But what is it about Aristotle's view of nature that makes it so distinct from the modern view? What did he see in nature that we seem to miss? In order to distinguish Aristotle's view of nature from the modern perspective we can, curiously enough, begin with the thinkers that came before him.

In the Physics, Aristotle continues the Hellenic tradition of inquiry into the physical world. But while Aristotle appreciates the groundbreaking efforts of his predecessors, he believes that they put too much emphasis on material elements, such as water (Thales) or air (Anaximenes) (Phys II. 2, 194a19-21). For many Presocratic thinkers, blind matter is the basic ingredient of nature: the fundamental nature of an animal is understood as consisting of flesh, bone and water, or its material elements. And when Democritus expresses the brilliant insight that nature is composed entirely of atoms moving in a void, the difference between the objects of perception becomes purely quantitative in its most fundamental sense. ${ }^{4}$ This view of nature is remarkably close to that of modern physics and is not entirely rejected by Aristotle. It is, however, seen by him as being incomplete. Aristotle's general view is hylomorphic - both matter (hulê) and form (morphê) play an essential role in the composition of the natural world.

As a student of Plato, Aristotle's claim that form must play a fundamental part in the constitution of nature should not come as a surprise. But where the Platonic conception of form generally has to do with an ideal conception of virtues that transcends particular or worldly instances - the "Form of Beauty" or the "Idea of the Good," for example - Aristotelian form concerns the diverse ways in which matter is informed; it deals with the things of the world, their appearances and what we say about them. Aristotle sees the world as fundamentally comprised of heterogeneous forms, not simply homogenous matter; he observes nature dividing into diverse entities that relate to each other through the purpose inherent in their respective forms. Indeed, there is a very strong sense in which, for Aristotle, the form is the individual being - this is true not only in terms of shape but with regards to purpose and meaning as well. For Aristotle, it is through the perception, or, more accurately, the "seeing" (theoria) of form that nature is knowable in a way that transcends matter and mechanics, and arrives at purpose. Aristotle sharply criticizes many of his predecessors (especially the Eleatics) for their departure from 
phainomena. For Aristotle, thinkers like Parmenides became too wrapped up in logical argument and failed to return to experience; the strangeness of their conclusions should have been an indication that there was something wrong with them. As Aristotle comments, “... although these opinions appear to follow logically in a dialectical discussion, yet to believe them seems next door to madness when one considers the facts. For indeed no lunatic seems to be so far out of his senses to suppose that fire and ice are one" (On Generation and Corruption I. 8, 325a-20). Aristotle also exposes problems in the thought of Empedocles, the Pythagoreans, and the Atomists with regard to generation and corruption, the possibility of motion, and the division of some notion of the "Whole" or the "One." 5

Aristotle's formal/teleological view of nature may be difficult for moderns to grasp, indoctrinated as we are with a largely material and non-teleological notion of nature that resonates more closely with the thought of the early Greek materialists like Democritus. How then does Aristotle see the relationship between matter, form and purpose as manifest in the world? A good place to begin to understand Aristotle's point of view is to consider the distinction he makes between those things that exist by nature and those things that exist for other or artificial reasons (Phys II. 1, 192b8-9). Aristotle sees a natural being as that which has "within itself a principle [(archê)] of motion and rest” (Phys II. 1, 192b15). ${ }^{6}$ He observes that natural beings come into existence and move towards their form - from a state of potentiality towards a state of actuality - by way of an innate principle of change. An unnatural being, by contrast, carries no such principle of change or movement within it. For example, a table, a bed, or a house has its principle of motion and being outside of itself - a human being(s) moved these objects into existence and gave them the attributes that make them what they are, both in the physical and abstract sense. These are works of artifice rather than nature (Phys II. 1, 192b2327). Heidegger sums up this insight and draws out the ontological necessity of movement in Aristotle's thought when he writes:

... [plants and animals] are beings only insofar as they have their essential abode and ontological footing in movement. However, their being-moved is such that the archê, the origin and ordering of their movedness, rules from within those beings themselves. (1998, p. 190)

As we have considered, the modern or ancient materialist would argue that the nature of the table, the house, or the tree lies in the material out of which it is made - wood in this case - and that as a result they are all fundamentally the same. By this light, any notions of form, purpose, or meaning, as real as they may seem to the "naked eye," are merely epiphenomenal - basic reality is homogeneous matter devoid of meaning. And, as seen through an object of techné (a microscope for instance), this idea is confirmed: the table, the house, the tree, and indeed everything is all made of the same "stuff" - molecules, atoms, and, finally, fields of force. On the level of direct experience, however, the view is quite different. The things of the world can only be experienced in any meaningful way inasmuch as they relate to each other as informed and value-laden states of matter. Wood is only potentially a table, a house or some other work of artifice or techné; it is material that has been stripped from the form of a natural being and reduced to potentiality. For Aristotle, the wood has no innate natural form in and of itself - it can only have meaning in terms of its potential ${ }^{7}$ to be assembled into an object of techné, or perhaps by virtue of the fact that it once participated in the self-actualizing form of a natural being (a tree). Thus, for Aristotle, the form of an object of experience is intimately associated with its 
meaning, whether it be artificial or natural. However, although the objects of artifice have form, they cannot properly be understood as having a nature (they have, rather, a techné); it is human desire and need that gives them purpose, and therefore they are meaningful only instrumentally and temporarily. Natural beings, on the other hand, are intrinsically and, in a sense, eternally meaningful - they are ends unto themselves. ${ }^{8}$

As we began to consider above, Aristotle's conception of potentiality and actuality is parallel to his view of matter and form (hylomorphism). And movement, as we have considered it thus far, is the actualization of potentiality, or the movement of matter towards form: actuality/form is more fundamental in nature than potentiality/matter and therefore natural beings contain within them a principle of movement towards their specific actuality/form - "the form is the nature more than the matter is" says Aristotle (Phys II. 2, 193b10). Thus we see the egg become a tadpole, and the tadpole become a frog; we observe the seed become a sapling, and the sapling become a tree. Each has within it its own principle or archê and each moves seamlessly towards its actuality, purpose, or telos. On the other hand, the purpose, form and coming into being of an artificial object is not self-actualizing. The form of artifice is wholly dependent on human need, desire, and techné, without which its actuality and meaning disappear, and the object reverts to pure potentiality as matter. Trees beget trees, but tables do not beget tables. Once again, experience is fundamental for Aristotle. His basic account of nature and artifice is neither metaphoric nor intellectual; rather, it is a direct description of the phenomena as they are experienced. As Aristotle points out, “... it is ridiculous to want to prove that phusis is, because this (being-as-phusis) appears of and by itself..." (193a3-9). And, as Heidegger adds, "In fact the whole undertaking is ridiculous [(proving the existence of phusis)]. The being of phusis and phusis as being remain unprovable because phusis does not need a proof, for wherever phusisbeing stands in the open, phusis has already shown itself and stands in view” (1998, p.201). Thus one does not need to (nor can one) prove that nature exists; it is, as Aristotle says, "evident." And indeed, one does not have to be as relentlessly observant as Aristotle in order to experience natural beings behaving purposefully in the world - one only has to look and see.

\section{Activity, Purpose, Soul}

We have just been looking at the way in which Aristotle sees beings move from potentiality in matter towards actuality as form; and how form itself allows us to experience the world - it is only through the perception of forms that move into and out of being that we can talk about or experience the world in any meaningful way. We also began to consider how Aristotle describes the experience of natural form as intrinsically purposeful - natural beings bear the principle (archê) of their own movement and meaning within them, they have a nature, while the form of artifice is necessarily instrumental and externally determined. In order to gain a deeper understanding of how this process of potentiality/actuality relates to form, purpose, and meaning in terms of the behavior of natural beings, we must now take a brief look at Aristotle's intertwined conceptions of cause and soul.

In order to understand a natural being, Aristotle claims we must begin with four fundamental questions that relate to its cause or telos (Phys II. 7, 198a25-28). The responses to these questions create an image of the principle or archê by which a specific natural being moves from potentiality into actuality, and therefore leads us to understand its purpose. If we are to understand the form of a natural being, according to Aristotle, we must first ask, "Of what is the 
being constituted, or what is its material cause?" Then we must ask, "What moves it, or what is its efficient cause?" Next we must ask, "What is it, or what is its formal cause?" And finally, we must ask, "What is its purpose, its final cause or telos?" 11

It is with this emphasis on formal and final cause that Aristotle breaks with both the modern and ancient materialist view. As we considered above, Aristotle shares the concept of material and efficient cause with the Presocratics and modern physics; and the concept of formal cause is inherited from Plato and developed by Aristotle. The idea of a final cause, however, is distinctly Aristotelian and it is here that he breaks with modern science, which tends to retreat from teleological questions. Additionally, Aristotle's teleological view not only asserts that all natural entities - not just humans - are intrinsically purposeful, but also claims that all living beings have souls (psuche). The fact that Aristotle extends this to plants may sound strange, but if we remember that, in his view, form and matter equate with actuality and potentiality, his conception of soul becomes clear.

The best way to understand Aristotle's conception of soul is, not surprisingly, to observe a growing, organic, living being. In a living being all of the matter that constitutes it is organized into parts that work towards the actualization of its form. For example, we may consider what Aristotle calls the "nutritive soul." Before it is eaten, food is actually different from the body, but potentially the same; after it is eaten, the food becomes actually the same as the body. Thus the activity of nutrition is precisely this causal process of the actually different but potentially the same becoming actually the same. It is this process, not some sort of separate entity, that Aristotle calls the nutritive soul. Indeed, one might consider this conception of soul as encompassing both the cause (aitia) and the principle (archê) of a living body (aitia kai archê) (De Anima II. 4, 415b8).

By nourishing itself, the being grows. And although it may get materially bigger, it always maintains a form. As we have considered, form is what the being is both potentially and actually. And because it has a form or a formal cause, the growing being also has a purpose, a telos, or a final cause. The purpose of the being is to become healthy and mature; to attain its form as fully as possible; and to strive towards its particular aretê or excellence. It is not only in its nature to do this, this process is its nature and, therefore, its purpose and meaning as well. For Aristotle, the soul of the being is, in a strong sense, the very activity the being engages in as it continually realizes and maintains the four causes as a life process. And, of course, this process is entirely related to the fundamental relationship of matter and form. Thus Aristotle's view of a natural being can be understood as the self-actualizing relationship of matter and form as it moves towards purpose. This process is directed by the unique principle of movement contained within the being. For Aristotle, this intertwined process is the soul of the being and is indicative of the kind of excellence particular to that being. And he is convinced that all of this is knowable to the human mind through the experience of nature as it presents itself to perception.

\section{The Flourishing Life: Orexis and Eudaimonia}

We have just been considering Aristotle's conception of soul as the life process of a being that is alive, active and potentially flourishing. Aristotle claims, "If an eye were an animal, sight would be its soul" (De Anima 412b11-22). And indeed, when a being is alive its matter is organized in a specific way and all of its parts are purposefully active - a living eye sees, whereas a dead eye is only an eye in name. And of course, Aristotle's conception of soul is not limited to the nutritive 
variety we examined above - he views the processes of perception and reason in much the same manner. As we have seen, Aristotle claims that all living beings have a nature - a specific function, or telos - that defines their potentialities in terms of their particular aretê or excellence. In the last section we discussed how, for Aristotle, the movement or activity of the nutritive soul works causally towards the health, maturity, and ultimately, the excellence and purpose of the being whose function is primarily nutritive (e.g. plants). And in terms of the activity and proper functioning of the souls of beings whose highest purpose is to engage in perception and reason animals and humans respectively - the perceptive and rational souls play fundamental and defining roles as well (De Anima II. 3-6). When a being perceives something, the experience of the phenomena becomes, in a sense, part of the being - perception moves the animal and contributes to its form. And likewise, the rational soul, special to humans, directs our purpose and function. ${ }^{12}$ But is there still a more fundamental and universal excellence or telos towards and because of which the "souls" of all beings move? Can we draw a proper connection between the view of nature we have been examining and a human sense of ethical value or "goodness" in general?

As we have begun to consider, much of Greek thought looks for ethical understanding not just from the philosopher's chair, but also through direct experience of the world. Socrates plays the proto-sociologist/psychologist and searches the marketplace in order to interrogate his contemporaries about justice, love and goodness. And Aristotle too takes up this approach in his own unique way - he examines ethics through the eyes of a biologist and anthropologist. Just as Aristotle observes the activity of beings in nature in order to discern the excellence and purpose of a given creature, so too in examining ethics he looks for the particular kinds of activities, character traits and structures of life that lead to excellence in the individual or community. He launches an enormous comparative study of individuals, societies, and social groups in order to attain direct insight into the goal and purpose of human life. In the Nicomachean Ethics, Aristotle claims that those human beings who can understand their function and fully actualize their nature are capable of reaching eudaimonia (happiness or, the flourishing life). Aristotle sees this as the of work of the soul - or, more accurately, the "activity [of the human (rational) soul] according to virtue" - and he claims that eudaimonia is the final good; human beings desire a good and flourishing life as an end in itself (NE 10. 6-7). For Aristotle, human eudaimonia finally depends on the functioning of the rational soul, while animals and plants depend on the perceptive and nutritive souls respectively in order to fully reach their purpose. However, although the term eudaimonia does refer specifically to humans and the rational pursuit of the "good life" (it would be presumptuous to say that animals or plants experience happiness just as humans do), it seems to me that the view I have just been discussing makes it very difficult to avoid considering the possibility that the proper activity, final purpose and soul of nature may lie in the heterogeneous flourishing, the eudaimonia, of all life.

In terms of Aristotle's thought proper, this view may seem problematic - especially in light of his idea that the form, purpose and soul of natural beings are contained within the individual beings themselves, and not as some external or universal entity, form or telos. A consideration of Aristotle's notion of a hierarchical cosmos may prove helpful here, but also raise new problems (more on this shortly). While I may be treading on rather shaky ground here in terms of Aristotle's thought proper, I hope that the advanced reader of Aristotle will, at least for the moment, allow me some latitude in order to strengthen my point.

Although the view I have put forward could arguably be seen as a departure in terms of Aristotle's ethical writings, I suggest that what I offer here need not be understood solely as a 
metaphor for the distinctly human type of flourishing Aristotle calls eudaimonia; rather, it can be arrived at through a direct affirmation of what is most natural in human experience, and of what connects us most profoundly and ethically with nature - purpose, love, the desire for goodness, a flourishing state of being and all that this entails. And indeed, in the larger scheme of Aristotle's writings, an enmeshment of the natural and moral orders can be discerned. Nussbaum outlines this beautifully by demonstrating the remarkable way in which Aristotle manages to break down the barrier between the two common, and seemingly irreconcilable, accounts of animal movement he encountered. ${ }^{13}$ On one hand, we have the purely physiological account that is associated with the materialistic conception of Being put forward by much of Presocratic philosophy and modern science. On the other hand we have, as both Nussbaum and Aristotle see it, the highly rationalizing position taken by Plato. In the Phaedo, Socrates does not object to the materialistic/physiological account of how he came to be sitting in prison (the one involving bones, sinews and so on). He does, however, reject the claim that this type of account can explain the cause, the aitia, of why he is sitting in prison. Socrates then sets out to examine cause in terms of intellect and rational deliberation - the examined life. Aristotle sees something problematic here: for him, the highly rationalizing approach of Plato tends to isolate humans from the very real forces of nature, desire, and belief, while, on the other hand, the purely materialist or physiological approach ignores everything but material and efficient causes. He is confronted, as Nussbaum puts it:

on the one hand, by a model of explanation whose aitia is so 'common' that it assimilates all intentional actions both to one another and to other cases of response to an external physical stimulus; on the other, with a model that is not "common" enough to do justice to our beliefs about what we share with "the other animals," and about what links together different elements in our own behavior. (Nussbaum 2001, p. 273)

For Aristotle, the reconciliation of these views is found in the universal need for all natural beings to reach out (orexis) to the world in order to fulfill their formal and final causes in the best way possible; and this may involve, in varying degrees and combinations, the activity of the nutritive, perceptive and rational souls, as well as desire and emotion. Aristotle claims, "if the soul is tripartite, there will be orexis in each part"; and "Intellect does not impart movement without orexis....” (De Anima 3. 9). Again, Nussbaum sums it up well: "we all [(natural beings)] reach out, being incomplete, for things in the world. That is the way our movements are caused" (2001, p. 289). And I should make it clear that this fundamental notion of movement that encompasses the process of potentiality/actuality, the aitia kai arche, is not to be understood simply as movement from place to place (although it is that), but also in terms of growth and diminution, nutrition, perception, rational activity and any kind of alteration, change or development (Cf. Heidegger 1998, pp. 189-90).

Following this view, it seems that there is a very strong sense in which our ethics begins with this movement, this reaching out to the world, which is informed most fundamentally by the direct appearances of things (phainomena). Indeed, as Nussbaum examines in some detail, our ethical selves are formed from birth by this reaching out with our senses, our souls and our minds to the world (nature, things, our parents and siblings, our society, other societies) in order to feel, intuit, and rationally understand our needs, desires, and reasons. ${ }^{14}$ Ethics, by this light, cannot be simply extracted from the non-rational categories of existence that give rise to it - it must be 
understood in the context of those enmeshed "external" and "internal” forces that cause the being to move and change. On the most practical level then, ethics is a qualitative "taking" of the world as we find it and a meditation on how we may best move (function or be active, physically, emotionally, rationally, politically, etc.) in this world towards eudaimonia.

Furthermore, and more generally, Aristotle points to the organic cosmos or nature as a whole as the best "thing" there is. In the Politics he seems to clearly express such a view when he writes: "because in every composite thing, where a plurality of parts, whether continuous or discrete, is combined to make a single common whole, there is always found a ruling and a subject factor, and this characteristic of living things is present in them as an outcome of the whole of nature" (Politics I. 1254b). Kohak shares this reading and draws out its moral significance when he writes:

That continuity of the vital and moral order becomes explicit in Aristotle, as, for instance, in the familiar Book I of his Politics. Here Aristotle explicitly equates the moral order with the natural order. The moral order is distinctive only inasmuch as humans, unlike their fellow animals, must grasp the order of the cosmos through an operation of intellect and choose to honor it as an act of will. While for beings endowed with instinct the operation of the law of nature is automatic, vital.... (Kohak 1984, p. 9)

And indeed, this conclusion resonates closely with the work of those thinkers who, like Kohak, are involved with modern ecological phenomenology and deep ecology, both of which I will consider in the following section.

So I suggest that if we can open ourselves to experience nature as a system of interrelated purposeful beings (of which we are a part) that reach out towards aretê, each according to its form and intrinsic principle of movement; and if we can recognize that the final good for any living being lies in the potential for that being to attain a flourishing life - to reach its potential as fully as possible - then the contemplation of nature necessarily becomes an ethical experience because the beings of the world (their purposes and enmeshed relations with each other) must be recognized as intrinsically meaningful each in their own distinct way. And because the nature of existence and experience is necessarily shared, this natural ethos should apply not only with regard to individual purpose, but in terms of a common telos as well. If we do indeed experience nature striving towards its fullest and most flourishing state of soul - in Aristotelian terms: rational, moderate, and virtuous eudaimonia in humans, perception and activity in animals, and nutrition in plants - and if we see this flourishing as the telos, the "that for the sake of which", or the final good, then the very transformation of matter that we take for granted in the modern world - building houses, tables, television sets, driving cars etc. - takes on a whole new meaning in the sense that it may deprive natural beings of their form, purpose and soul, and, ultimately, reduce goodness.

As this ethical view of nature is derived from an experience of the world that recognizes the basic necessities required for beings to achieve their potential - cultural and psychological assumptions, as well as purely cognitive theorizing, play little or no role here - it would seem to be largely resistant to relativistic or completely intellectual positions. On this more fundamental level of experience, complicated utilitarian and rationally-dependent ethical theories (as well as Aristotle's own virtue ethics for that matter) need not apply. Indeed, this view derives its truth from the immediate "seeing" of the world, not as an object of conscious thought as such, but 
rather as an undeniable, innocent, and altogether ethical experience of existence that naturally perceives purpose in nature and senses the flourishing of life as innately good. I suggest that in denying this experience we deny what is most natural in ourselves and, by consequence, what is most human.

At this point I must address a difficult issue that I touched on above - one that may well be a growing cause of concern for some readers. The notion of the hierarchical cosmos that pervades much of Aristotle's work offers a conception of the universe as an orderly place in which the creatures and things of the world function according to their place in existence. According to Aristotle, those beings that most fully achieve their place in the cosmic hierarchy can be said to be truly excellent creatures - this is in accordance with what I have been outlining thus far. However, in terms of the larger point this paper strives to make, Aristotle's the notion of the hierarchical cosmos is problematic. Although it does seem to link Aristotle's heterogeneous view of nature with some overarching cosmic order, it turns out that the hierarchical cosmos is highly anthropocentric. And furthermore, by stationing women as second-class beings the hierarchical cosmos also reveals a clear misogynist bias in Aristotle's thought (surely due in no small part to the $4^{\text {th }}$ century cultural milieu in which he found himself). Indeed, it has been argued that Aristotle's hierarchical cosmos simply reinforces the view that sees the purposes of non-human beings as subordinate to those of humans (and everything as subordinate to a distinctly male rationality); and that this simply reflects the problematic way in which many people actually engage with the natural world - that is, through a kind of ethical ranking that hierarchically structures the world in a way that asserts the superiority of distinctly human ends. Understandably, this has led some to dismiss Aristotle's view of nature outright (and his apparent anthropocentrism is clearly at odds with the view of nature I discuss in the next section and for which I have been arguing all along). But this raises the question of whether or not it is necessary to be in total agreement with a thinker before one may begin to employ some of his or her ideas, methods or observations as starting points from which one may formulate one's own conception of things. Indeed, history is full of thinkers who may have forged what we now take to be incorrect, even despicable conclusions but whose thought nonetheless contains brilliant, useful and even beautiful insights into the human condition and the nature of reality. I should make it clear, then, that I do not see Aristotle's hierarchical cosmos as some kind of a priori conception with which his direct observations (those I have been outlining all along) are forced to comply. Rather I view it as a secondary speculation - albeit one that is central to much of Aristotle's political theory - that emerges out of his initial observations of nature and inquiries into human social activity. While it may be of interest to examine the theoretical and cultural reasons why Aristotle structures his cosmos the way he does, such a project is beyond the scope of this paper. Suffice it to say that while I too part with Aristotle in terms of the ethical and practical implications of his (as I see it) speculative hierarchical cosmos, I still believe that the more basic and direct phenomenal account he gives of the world - his distinction between natural and artificial; his notions of movement, cause, potentiality, actuality, soul, orexis and hylomorphism offers us a great deal to consider.

Whether or not we agree with every aspect of Aristotle's account of things, the experience of nature he describes to us should, at the very least, inspire the recognition that as individuals we do possess a natural capacity to experience the world in a meaningful or "value-laden" way. I suggest that Aristotle's example may offer a starting point from which we may begin to examine the world for ourselves; and that in doing so we may begin to see the things of nature (or indeed, those things with a nature) more like proper subjects rather than objects. ${ }^{15}$ Heidegger's reading of 
Aristotle may take us further still, beyond the anthropocentric subject/object dichotomy, to recognize that nature (phusis) has a deeper significance of its own. Indeed, Heidegger's insight that our experience of the world does not begin with a recognition of subjects and objects owes a great deal to his understanding of Greek thought in general and Aristotle in particular. Discussing Aristotle's conception of phusis he writes:

But beings can be experienced as objects only where human beings have become subjects, those who experience their fundamental relation to beings as the objectification - understood as mastery - of what is encountered. For the Greeks, human beings are never subjects, and therefore non-human beings can never have the character of objects (things that stand-over-against). Phusis is what is responsible for the fact that the stable [(that which stands by itself and of itself, i.e. natural beings)] has a unique kind of standing-on-its-own. ... [U]nder the spell of our modern way of being, we are addicted to thinking of beings as objects and allowing the being of beings to be exhausted in the objectivity of the object. But for Aristotle, the issue here is to show that artifacts are what they are and how they are precisely in the movedness of production.... Above all he wants to show that this movedness has another archê [(techne)] and that beings that are moved in this other way are related to their archê in a different manner [(through techné)]. ... No doubt a good deal of time has yet to pass before we learn to see that the idea of "organism" and of the "organic" is a purely modern, mechanistictechnological concept, according to which "growing things" are interpreted as artifacts that make themselves. Even the word and concept "plant" takes what grows as something "planted," something sown and cultivated. (Heidegger 1998, pp. 189-98; Cf. Physics II. 192 b12-13)

Heidegger's words also begin to reveal the challenge our culture imposes on the project of a qualitative, ethical understanding of nature: in order to "open up" to the experience of nature we must also create a "clearing" in our own received ideas and assumptions of it; thus the rediscovery and acceptance of our most direct and innocent experience of the world will necessarily be a critical undertaking as well. As Heidegger points out, the ability to distinguish between natural beings and artifice is a "krinein in the genuinely Greek sense: separating out what is superior from what is inferior." And indeed, for Heidegger and Aristotle, those who cannot make such a critical distinction are "blind to phusis” (Heidegger 1998, p. 202). So while Aristotle's writings may inspire us to “open up” to a direct and meaningful experience of nature, for us moderns, in practice, this is certainly more easily said than done.

Over the centuries we have systematically rejected the most naturally human view of the world, and have given truth and meaning over to science and technology almost exclusively (eros has become directed by the products they produce). This has often skewed the practice of philosophy, history, economics, and modern cultural activity in general, towards the brilliance of human artifice and the ideology of progress - the proper development and understanding of human orexis seems to be in a state of crisis. The atrocious events of the 20th century (the two World Wars, the Holocaust, Hiroshima and Nagasaki among many others) have increasingly pushed us to question the modern humanist/rationalist view of the world and to recognize the dangers inherent in our technological culture. The technological achievements of the 20th Century have also allowed us to look back on our planet from outer space - a perspective that has 
had profound metaphysical and existential implications with which we have not yet come to terms. And now, in the 21st century, we face unprecedented environmental and economic challenges. Although our mode of existence seems completely at odds with the changes we need to make, we can no longer hide from the uncertainty of our condition in consumerism - we must, finally, face our problems head on. Clearly, this is going to involve a complete reworking of almost every aspect of our culture and, perhaps most fundamentally, a new understanding of nature and what it means to be human. While phenomenology itself cannot provide direct solutions to the problems we face, it can offer us a method by which we may begin to see the relationship between the world and ourselves in a more primordial sense. Indeed, this perspective may offer a starting point from which we might begin to rework our ethical sense of the relationship between science, technology, humanity, and nature - one that begins with the individual's direct experience of the world. In the concluding section I will briefly examine the modern attempts to embrace the mode of seeing the world that seemed so natural for Aristotle in the 4th century B.C.; and I will consider how this phenomenological view might begin to be integrated with our current understanding of the individual as a political animal, as well as with our technological culture in order to open us up to a more authentic view of ourselves and Being itself.

\section{Phenomenology and the Ethical Experience of Nature}

As we have considered, the modern scientific and philosophical view is very critical of Aristotle, ${ }^{16}$ as it rejects the possibility that human perception is capable of knowing the true causes of things - any purposes that humans think they see in nature are merely psychological projections or superstitious fabrications. ${ }^{17}$ For modern science, all things in nature proceed from necessity; and the goal of scientific inquiry is to discover the universal laws that determine this necessity. However, as Husserl points out in The Crisis, the scientific age has paid a price for rejecting the purposeful experience of nature that comes from the kind of naturally human point of view that Aristotle embraces. Mired in technology, we have lost sight of the natural sense of the world. Truth has become simply a product of the correlation of events to predictions - or the rendering of logically-balanced statements that resist contradiction. As a result, ethical understanding too comes to be determined by language and techné; we take it as given that it is human reason that must impose ethical meaning onto the world. But the idea that the human mind might be, as a part of nature itself, perfectly suited to interpret or, indeed, "see" the meaning of things as nature gives it to experience is not a view that the scientific age accepts as valid. ${ }^{18}$

The modern scientific view of the world is gained through the microscope, the telescope, the abstraction of mathematics and the algorithmic power of the computer. And, thanks to the technology provided by scientific discovery, the things of the world can be manipulated as if they were merely the passive objects of the human will. For modern science, nature is homogenous in its most basic state - understood as blind matter acting in accordance with knowable laws, it is purposeless and therefore not a proper subject for ethics. And indeed, teleological conceptions of nature, such as Aristotle's, were scoffed at in the Scientific Age. After all, an approach to the study of nature that strives to see the inherent purpose in it is necessarily at odds with a program that seeks to transform it. Aristotle's view of the physical world is almost completely useless to any kind of technological program as it strives to see nature as it is, not as it might be used to 
serve human purposes - theoria seeks knowledge for its own sake, as a human virtue that leads to eudaimonia, and not instrumentally for the sake of progress or technology.

While the modern view of the world has allowed us to create what can only be described as technological miracles, it has also estranged us from nature and, many would argue, from an authentic and purposeful experience of life itself. It has imposed a cultural model that allows us to use nature and science instrumentally towards increasingly irrational ends. Nature, as well as the creatures and objects - or, as we call them, resources ${ }^{19}$ - found within it, are viewed as being purposeful only insomuch as they serve our desires. According to our subject/object technoculture as it descends from Bacon and Descartes, nature, once "understood" by the laws we "discover" and impose upon it, becomes an object that human reason molds with the tools of technology. By this view, mind and world are ontologically-distinct entities and nature becomes an object of human consciousness rather than its condition. And, as the modern cultural agenda is one of progress, science often turns away from the task of seeing and knowing goodness, and is conflated with and led by technology and the creed of progress and economic growth. The natural world provides fuel for the machine: The forests are vast stores of material with which we make the products that drive our economy - that is the purpose we give them. Or, conversely, they become objects that stand in the way of agriculture, herding, or transportation infrastructures and must be removed - they are relatively purposeful or purposeless only in relation to our needs and desires. Animals too, finally, are simply machines and/or sources of meat. ${ }^{20}$ And what of ourselves? What is our telos in the modern age? Is our final purpose as individuals simply to serve as the digestive tract of the economic machine? Or are we more than simply the all-important worker/consumers?

In the 21st century, we find ourselves faced with a crisis that is as metaphysical as it is physical, as ethical as it is existential. We find ourselves struggling with our relationship to nature and, by consequence, ourselves. Our "reaching out" (orexis) to the world is increasingly checked at every turn by artifice and advertising and as a result we tend to construct our ethics around culture and economy rather than through those natural and universal elements that permeate Being. Indeed, we have come to dismiss the most fundamental way in which we know the world - today, the acceptable source of knowledge comes not from our own senses and experience but rather through the lens of science and technology. We accept as fact that truth, meaning and goodness are not in nature but rather in the artifice we produce. We have adopted the position that purpose is an attribute that is given by human reason rather than something that lies in the experience of nature. And we have lacerated ourselves from natural meaning by creating an artificial existence whose purpose is increasingly unclear, and whose ramifications may be potentially disastrous for all life on earth.

In the first half of the 20th century, thinkers like Husserl and Heidegger were already concerned about the problems inherent in a highly technological society. In different ways they both tried to reconnect with an authentic, natural experience of the world through an examination of human consciousness. Husserl's phenomenology is the study of the essential structures of experience and subjectivity, and as such it provides the first real method for existential investigation into the self and human consciousness. Husserl attempted to correct what he saw as fundamental problems and misunderstandings in the philosophical legacy of Descartes - the essentially dualist conception of world and mind for instance - but he remains committed to the Cartesian prospect that human conscious is essentially intentional. That is, he believes that consciousness is always and necessarily about something. Heidegger develops the phenomenological idea by breaking with Husserl and the entire Cartesian project. Although 
Heidegger does not reject the concept of intentionality, he does not see it as the most fundamental aspect of human experience. ${ }^{21}$ He posits that our most primordial experience is not intentional at all - it is, rather, a unified experience of being in the world. Like Aristotle, Heidegger attempts to understand the nature of being as such, but in doing so he discovers that focusing on intentionality gives us only part of the picture. As a result, Heidegger does not talk about consciousness, subjectivity, objects or intentionality, nor does he use the term "human being."22 Instead he employs the wonderful word "Dasein” which literally means "being there," both in terms of place and time. He does this because he thinks that from the "innocence" ${ }^{\text {,3 }}$ of the first-person perspective - that is, the view of the world from the fundamental and most natural vantage point of "sheer presence" - the question of what we are in the world remains to be determined. For Heidegger, it is this state we must contemplate if we are to discover our primordial selves.

If Heidegger speaks of consciousness at all it is never directly and only has to do with the fundamental way in which it opens us up to being as such for query. But where most philosophers would agree that we are essentially questioning creatures - remember Aristotle's claim that "all human beings by nature desire to know" - Heidegger refuses to discuss this first in terms of subjectivity or intentionality. ${ }^{24}$ Indeed, there is a strong sense in which the kind of ontological questioning that Heidegger posits as primordially human is not directed towards the world or Being, but arises because of it: Heidegger shows that the conception of the detached self that examines the world is incomplete - the being is, before anything else, in-the-world. And this explains why the Cartesian cogito ergo sum is such a misleading paradigm of self-identity. For Heidegger, this split between mind, body and world is disastrous, not only because it leads to the assumption that self-knowledge is immediate and transparent, but also because it allows us to adopt the false view of the world as a resource - this perspective betrays our own nature and, in the process, the true nature of our relationship to the world. For both Heidegger and Husserl, we become diminished beings when we engage in competition and consumerism, or when, as a culture, we allow ourselves to become blinded by the glare of technology. For them, this kind of activity removes us from authentic engagement with others and the world at large.

There is indeed a strong ecological aspect to the thought of Heidegger, and recent decades have seen thinkers like Zimmerman, Naess, Evernden, and Kohak employ aspects of his way of looking at the world - as well as the developments made by thinkers associated with him - in order to reconnect philosophical thought with the human experience of nature. In an attempt to rediscover our most innocent, embedded and primordial experience of the natural world, this phenomenological view seeks to lay bare the fundamental experience of nature by "bracketing out" economic, social, historic and scientific evaluations of it. However, ecological phenomenology, and the deep ecology that is so closely associated with it, strives to offer more than just a way of opening up to a "pure" experience of nature. It goes further and claims to offer a necessary response to the modern obsession with technology and the reductively quantitative accounts of the natural world that enable the very instrumental view of nature I was bemoaning above.

The position of ecological phenomenology and deep ecology resonates with the views of Aristotle, and with the ethical telos of the flourishing life I was discussing earlier. But it also owes a great debt to Heidegger's conception of "care” - this sense of nature as pure presence; or the primordial concern for Being as such that transcends the notion of the world as a collection of neutral matter or things and sees it as something we "live though." ${ }^{25}$ Generally speaking, ecological phenomenology and deep ecology sees the well being and flourishing of all life on 
Earth as a universal good; it views the beings of the world as intrinsically purposeful - the true value of natural beings is independent from human intention - it sees the heterogeneity of natural forms, including geographical formations such as mountains and bodies of water, as contributing to the overall value of nature; and it claims that any human activity that works against the innate purpose of natural forms, or the overall flourishing of life, violates a fundamental natural ethos. Finally, it calls for the introduction of new policies that take this natural ethos into account within the spheres of human social, economic, philosophical and scientific discourse. Indeed, this position asks us to "see" the world in a way that is both new and primordial at the same time. It asks us to distinguish human artifice and assumptions from natural purpose so that, finally, we might rediscover our own relationship with the natural world and come to see ourselves not as the center of creation or "in-nature," but rather as an enmeshed part of Being as such.

In the context of our modern culture, the recognition of this view necessarily involves an uncovering of the true meaning of human being - a reaffirmation of our own nature as meaningful beings through the recognition of our own natural experience as a primal and fundamental truth. But this does not presuppose the abolition or dismantling of science and technology - such a suggestion would be as ridiculous as it is impossible. Rather, it requires a rethinking and clarification of its meaning and purpose. Indeed, techné, reason and artifice are a part of what it means to be human. Pointing to Heidegger, Kohak writes, "Technology... is not only a convenience but also an authentic human possibility." He continues, "[Mankind] is an artificer not by accident but essentially.... If the products of human techné become philosophically and experientially problematic it is, I would submit, because we come to think of them as autonomous of the purpose which led to their production and give them meaning" (Kohak, pp. 23-24). This speaks to why the phenomenological bracketing introduced by Husserl works so well in an ecological context. It offers a means by which the true meaning of human artifice can be affirmed by giving it an experiential grounding - it allows us to transcend our psychological notions of artifice and begin to see it for what it is: a part of our capabilities as natural beings, a part of the way we "reach out to the world"; rather than, falsely, an end in itself. Naess expresses this insight in more explicitly practical terms:

"The implementation of ecologically responsible policies requires in this century an exponential growth of technical skill and invention - but in new directions, directions which today are not consistently and liberally supported by the research policy organs of our nation states.” (Naess 1973, p. 95)

The practical question of how we might begin to direct human potential and capability (techné, reason) towards ecologically-aware action and policies remains open. However, Naess' 1973 paper, "The Shallow and the Deep, Long Range Ecology Movements"26 offers a useful starting point. Naess begins by defining the difference between: I) The Shallow Ecology movement, which simply fights against pollution and resource depletion - the central objective being "the health and affluence of people in the developed countries” - and II) The Deep Ecology movement that:

(1) Rejects the "man-in-environment image in favour of the relational, total-field image”

(2) Asserts a principle of "Biospherical egalitarianism” that promotes a “deepseated respect, or even veneration, for ways and forms of life... equal right to live 
and blossom is an intuitively clear and obvious value axiom. Its restriction to humans is an anthropocentrism with detrimental effects upon the life quality of humans themselves...."

(3) Promotes an awareness of "diversity and of symbiosis" with the recognition that:

Diversity enhances the potentialities of survival, the chances of new modes of life, the richness of forms. And the so-called struggle for life, and survival of the fittest, should be interpreted in the sense of the ability to coexist and cooperate in complex relationships, rather than the ability to kill, exploit, and suppress. "Live and let live" is a more powerful ecological principle than "Either you or me." The latter tends to reduce the multiplicity of kinds of forms of life, and also to create destruction within the communities of the same species. Ecologically inspired attitudes therefore favour diversity of human ways of life, of cultures, of occupations, of economies. They support the fight against economic and cultural, as much as military, invasion and domination, and they are opposed to the annihilation of seals and whales as much as to that of human tribes and cultures.

(4) Embraces an Anti-class posture consistent "with wide and widening classless diversity."

(5) Fights against pollution and resource depletion, but is wary of projects that may reduce pollution but increase "evils of other kinds."

(6) Embraces complexity, not complication:

Organisms, ways of life, and interactions in the biosphere in general, exhibit complexity of such an astoundingly high level as to colour the general outlook of ecologists. Such complexity makes thinking in terms of vast systems inevitable. It also makes for a keen, steady perception of the profound human ignorance of bio-spherical relationships and therefore of the effect of disturbances.

(7) Promotes local autonomy and decentralization:

The vulnerability of a form of life is roughly proportional to the weight of influences from afar, from outside the local region in which that form has obtained an ecological equilibrium. This lends support to our efforts to strengthen local self-government and material and mental self-sufficiency. But these efforts presuppose an impetus towards decentralization. Pollution problems, including those of thermal pollution and recirculation of materials, also lead us in this direction, because increased local autonomy, if we are able to keep other factors constant, reduces energy consumption. (See Naess 1973, pp. 95-100)

Naess goes on to recognize that many of the "formulations" made in his seven point "survey" are vague and that they must be subject to the conditions and contingent needs of the situation at hand (and the relationship between local and distant factors) which must be carefully examined. However, Naess' seven formulations do begin with basic phenomenological insights into the value of nature and the basic necessities required for a flourishing life. And these insights 
resonate with those of Aristotle: “... an ecosophy, however, is more like a system of the kind constructed by Aristotle....” (Naess 1973, p. 100)

In face of the now dire environmental crisis, the work of thinkers like Naess seems more crucial than ever. Indeed, many modern thinkers struggle to find convincing ways to make nature a "player" in the arena of public policy. But before these models can be effectively transposed into the realm of human political structures they must be founded on a more fundamental ethical sense of nature that resonates as true on an individual level. Without a firm grounding in an ethos based on a personal understanding of nature as meaningful in and of itself, these well-intentioned but often metaphoric and anthropomorphic/centric notions of natural rights may be discarded or manipulated according to political whims or economic pressures. Ecological phenomenology and Deep Ecology strive to open us up to experience precisely this true ethical sense of nature on an individual level so that we may begin to integrate a personal experience of natural purpose into our social and political lives.

In our complicated technological society, legitimacy and notions of rights and justice so often seem to come to us by way of a "top down" political/scientific hierarchy. Information and its diffusion have become increasingly specialized and the individual tends to feel increasingly powerless in face of the complexity he or she faces. This results in a passive attitude towards knowledge, ethics and political engagement, as well as a turning away from the value of individual human experience. Phenomenology attempts to respond to this by placing the responsibility for seeing the ethical sense of things back on the individual as part of an active process of engagement with the world. Just as Aristotle places philosophical inquiry and political engagement high on the list of those natural activities of the human soul that lead to the excellence of the rational animal, so phenomenology places responsibility in the hands of the individual to determine his or her own authenticity and ethical outlook - to take responsibility for his or her own experience of the world. For Heidegger, authenticity revolves around the individual's "throwness" into the world, and the integrity, originality and honesty with which the individual creates his or her own authentic subjectivity from the starting point of "sheer presence”, only to reintegrate it back into society. For Heidegger, it is precisely by way of personal authenticity that we most effectively participate in society - those who rely solely on the perceived opinions of others or the cultural narrative of society in order to construct their ethical understanding of the world are doomed to an inauthentic existence. But while phenomenology concerns itself with an examination of direct experience, it also affirms that this experience is necessarily predicated on the existence of others. Indeed, phenomenology reveals the existential responsibility to examine and question our experience (of nature, culture, society, and others) directly, but this responsibility also requires us to share these experiences openly and passionately with our children, our community, and our government. Merleau-Ponty expresses this insight beautifully:

My own field of thought and action is made up of imperfect meanings, badly defined and interrupted. They are completed over there, in the others who hold the key to them because they see sides of things that I do not see, as well as, one might say, my social back. Likewise, I am the only one capable of tallying the balance sheets of their lives, for their meanings are also incomplete and are openings onto something that I alone am able to see. I do not have to search very far for the others: I find them in my experience, lodged in the hollows that show what they see and what I fail to see. Our experiences thus have lateral 
relationships of truth: all together, each possessing what is secret to the other, in our combined functioning we form a totality which moves toward enlightenment and completion.... We are never locked in ourselves. (1978, p. 138)

In terms of our relationship to the environment, Kohak suggests that an "ecological ethic" may be discovered through the "radical opening of our life and thought to the world of others, human, animate, inanimate, in the integrity of its otherness and the meaningfulness of its being" (1984, p. 207). And indeed, ecological phenomenology seeks an ethical perspective that is based on the active and reciprocal nature of inter-subjective experience - world, body and mind are, most fundamentally, an integrated system of experience and activity engaged in an ongoing process of self-actualization. Thus in every aspect of our becoming we must consider the Other and the All in terms of the ethical implications of our actions. So while the practical aspects of effective ecologically-minded policy making that Naess and others offer is crucially important, these policies, in order to be effective and true, must resonate with and be based on a synthesis of scientific knowledge and a deeply personal understanding of nature as a good in itself - it is our phenomenological responsibility as citizens and as natural beings to share and develop this understanding through our speech and actions (as consumers, creators, parents, artists, teachers, friends, politicians and beings in the world).

Phenomenology offers a return, a fresh approach to the original question of philosophy as it was raised by the Greeks, namely, “what is Being?” Just as Aristotle's theoria prompts us to look beyond the gates of the city in order to better know the forms and purposes of natural beings, so too phenomenology offers us a philosophical perspective that may aid us in clearing away the noise of culture, civilization and technology so that we might experience nature and ourselves in a more direct way: as an interrelated and changing system of intrinsically purposeful beings and things all reaching out towards the universal goodness of the flourishing life. And perhaps it is the innocent contemplation and expression of this experience that is the basic purpose of the natural human - the most fundamental activity of the soul of the rational animal, the philosopher, Dasein, or the being who contemplates Being.

\section{Endnotes}

1 Roochnick brings out the Husserlian concerns and their relevance to Greek philosophy beautifully. This paper takes many of his basic observations as its starting point. See Roochnick 2004, pp. 4-5.

${ }^{2}$ In a sense, this view prefigures Karl Popper's insistence that the scientific value of a given statement is largely determined by its falsifiability.

${ }^{3}$ The term "phainomena" is problematic for scholars of Aristotle. As Nussbaum points out, in the Eudemian Ethics these phainomena are "both the 'witnesses' and 'paradigms' that we are to use in philosophical inquiry.” Thus Aristotle's idea of examining phainomena entails something rather different than a hard, "theory-free" Baconian data collection: It is a broad notion that may take on differing forms and interpretations - like experience itself - and extends to what we say and believe about things. See Eudemian Ethics I2I6b26. Cf. Nussbaum 2001, Ch.8. 
${ }^{4}$ See Nussbaum’s illuminating “dialogue” between Democritus and Aristotle in Nussbaum 1978, pp. 59-99.

${ }^{5}$ See On Generation and Corruption Book I, Chapter 8.

${ }^{6}$ Again, this statement is not a pronouncement of fact. Rather, it is more like an expression of an experience of the world that invites further investigation and interpretation. I must also point out here that when I discuss Aristotle's idea of nature and natural beings, what I am really referring to is his idea of "phusis" and "ta phusei onta." Because this paper extends beyond Aristotle's ideas proper into those of modern thinkers and our own relationship with what we call "nature," I have translated phusis as the English word "nature" for the sake of convenience. The reader should be aware, however, that this translation is problematic. Indeed, in Heidegger's discussion of phusis in "On the Essence and Concept of Phusis," he points out that he purposively leaves phusis untranslated because the words natura or "nature" are "too ambiguous and overburdened, and, in general, because they get their validity as names for phusis only by means of a peculiarly oriented interpretation of phusis.” For more on this see Heidegger 1998, especially pp. 198-99.

7 “... for wood is potentially a box and is the matter of a box” (Met 9. 7, 1049a22 - 24).

8 “Techné can merely cooperate with phusis... but it can never replace phusis...." Heidegger discusses human techné as the archê of artifacts at length in "On the Essence and Concept of Phusis" (Heidegger 1998, pp.191-98). This insight gets a complicated new twist in the late $20^{\text {th }}$ century with the introduction of genetic modification, in vitro fertilization and so on.

${ }^{9}$ Clearly, Aristotle sees matter as natural - it takes on forms, disperses and forms again. It is however, only an aspect of the nature of things.

${ }^{10}$ In the Metaphysics, Aristotle takes up an analysis of "beings qua being." This is to say he undertakes, generally speaking, the task of answering the question: in so much as a thing can be said to exist, to what degree does it exist? For Aristotle, trees and wooden tables do exist in different degrees in the sense that the existence of a table is parasitic on the existence of a tree the existence of tables is predicated on the existence of trees but the existence of trees has nothing to do with tables.

11 " [T] while that from which the primary motion comes is the same in them in species: for man generates man, and so too generally in the case of things which cause movement being themselves moved” (Phys II. 7, 198a25-28).

${ }^{12}$ For Aristotle, all living creatures have the capacity for nutrition, some add to this the capacity for perception and desire, while humans possess all capacities including nous, or abstract rational thought (De Anima II. 3, 414b32-33).

${ }^{13}$ See Nussbaum 2001, Ch.9.

${ }^{14}$ Ibid Ch.9 part V. 
${ }^{15}$ See Evernden, Ch. 4, “A Biology of Subjects.”

${ }^{16}$ One should keep in mind that Aristotle was not ignorant of the kinds of criticism that modern science levels against him. After all, his work responds to the rationalizing Eleatic and Platonic approach as well as to the materialism of Democritus and Empedocles, which, in terms of basic principles, is not so distant from modern science.

${ }^{17}$ See Spinoza, B., Ethics, Appendix to Part I.

18 "Humans must suspend lived experience to produce the 'scientific world view' of physics. Our direct awareness of nature as the meaningful context of our lives, by contrast presents itself spontaneously, without a subject's effort. If anything it requires the opposite: to suspend effort, to let be and listen, letting nature speak” (Kohak, p. 6).

19 "By describing something as a resource we seem to have cause to protect it. But all we really have is a license to exploit it” Evernden, p. 23.

${ }^{20}$ See Evernden, p. 77.

${ }^{21}$ For Heidegger, it is only when we begin to deliberate on the particulars of an object with which we are engaged that they properly become objects or things at all. He discusses the levels of conscious engagement with the world most famously with the terms "ready-to-hand" and "present-to-hand." See Blattner pp. 50-6, 64.

${ }^{22}$ Heidegger s project in Being and Time is to describe the essence of being - that is, as stripped from notions of material causes and frameworks. As result, the normal terms we use for things and objects cannot be used lest they defeat his purpose. Indeed, one could say he is extending Aristotle's conception of form as an essential part of being as such.

23 "Perhaps we may think of phenomenology as a kind of deliberate naivety through which it is possible to encounter a world unencumbered with presuppositions. It is a formal resistance to the kind of reality-censorship of Galileo when he declared size and shape to be real, smell and color unreal.” Evernden p. 57.

${ }^{24}$ Otherwise he would be forced to return to a dualistic Cartesian position, as this would impose an observer who, most fundamentally, questions the things of the world as objects.

25 'Here, however, 'Nature' is not to be understood as that which is just present-at-hand, nor as the power of Nature. The wood is a forest of timber, the mountain a quarry of rock; the river is water-power, the wind is wind 'in the sails.' As the 'environment' is discovered, the 'Nature' thus discovered is encountered too. If its kind of Being is as ready-to-hand is disregarded, this 'Nature' itself can be discovered and defined simply in its pure presence-at-hand. But when this happens, the Nature which 'stirs and strives', which assails us and enthralls us as landscape, remains hidden. The botanist's plants are not the flowers of the hedgerow; the 'source' which the geographer establishes for a river is not the 'springhead in the dale." Heidegger, Being and Time, p. 100. Cf. Evernden p. 66. 
${ }^{26}$ Originally published in Inquiry (Oslo), 16 (1973). Available at: http://www.alamut.com/subj/id eologies/pessimism/Naess_deepEcology.html

${ }^{27}$ Naess expands this: “Organisms as knots in the biospherical net or field of intrinsic relations. An intrinsic relation between two things $A$ and $B$ is such that the relation belongs to the definitions of basic constitutions of A and B, so that without the relation, A and B are no longer the same things. The total-field dissolves not on the man-in-environment concept, but every compact thing-in-milieu concept-except when talking at a superficial or preliminary level of communication.” (Naess 1973)

\section{References}

Bacon, F. (1989). New Atlantis and the Great Instauration. Wheeling, Il: Harlan Davidson.

Blattner, W. (2006). Being and Time: a Reader's Guide. London: Continuum.

Barnes, J. (1982). Aristotle. New York: Oxford UP.

Barnes, J. (ed.). (1995). The Cambridge Companion to Aristotle. New York: Cambridge UP.

Barnes, J. (2001). Early Greek Philosophy. London: Penguin Classics.

Baudrillard, J. (1970). La Société de Consommation. Paris: Éditions Denöel.

Cardman, T. and Hansen, M. (eds.). (2005). The Cambridge Companion to Merleau- Ponty. New York: Cambridge UP.

Cross, R.C., et al. (1964). Knowledge Belief and the Forms. Plato's Republic: A Philosophical Commentary. U.K.: MacMillan.

Descartes, R. (1968). Discourse on Method and the Meditations. London: Penguin Books.

Dobson, A. (2003). Citizenship and the Environment. New York: Oxford UP.

Dodds, E.R. (1968). The Greeks and the Irrational. Berkeley and Los Angeles: University of California Press.

Dodds, E.R. (1973). The Ancient Concept of Progress. Oxford: Clarendon Press.

Dreyfus, H. (1991). Being-in-the-World: A Commentary on Heidegger's Being and Time. Cambridge, Mass.: MIT Press.

Evernden, N. (1993). The Natural Alien. Toronto: University of Toronto Press. 
Foster, S. (2002). Aristotle and the Environment. The Journal of Environmental Ethics, 24, pp. 409-28.

Gadamer, H.G. (1986). The Idea of the Good in Platonic-Aristotelian Philosophy. (P. Christopher Smith, Trans.). New Haven, CT: Yale UP.

Guignon, C. (ed.). (1993). The Cambridge Companion to Heidegger. New York: Cambridge UP.

Heidegger, M. (1962). Being and Time. New York: Harper \& Row.

Heidegger, M. (1977). The Question Concerning Technology. New York: Harper \& Row.

Heidegger, M. (1998). On the Essence and Concept of Phusis in Aristotle’s Physics B, I. Pathmarks. Cambridge: Cambridge UP.

Husserl, E. (1970). The Crisis of European Sciences. Evanston: Northwestern UP.

Irwin, T. (1977). Plato’s Moral Theory. Oxford: Clarendon.

Kant, I. (2005). The Moral Law: Groundwork of the Metaphysic of Morals. (H.J. Paton, Trans.). London: Routledge.

Kirk, G.S., Raven, J.E. and Schofield, M. (1983). The Presocratic Philosophers. Cambridge: Cambridge UP.

Kohak, E. (1984). The Embers and the Stars. Chicago: U of Chicago P.

Kuhn, T. (1996). The Structure of Scientific Revolutions. Chicago: U of Chicago P.

Long, A.A. (1999). The Cambridge Companion to Early Greek Philosophy. New York: Cambridge UP.

Lovelock, J. (2007). The Revenge of Gaia. New York: Basic Books.

McKeon, R. (ed.). (2001). The Basic Works of Aristotle. New York: Random House.

Merchant, C. (1989). The Death of Nature. New York: Harper Collins.

Merleau-Ponty, M. (1945). Phénoménologie de la Perception. Paris: Gallimard.

Merleau-Ponty, M. (1978). Adventures of the Dialectic. Evanston: Northwestern UP.

Naess, A. (1973). The Shallow and the Deep, Long-Range Ecology Movement: A Summary. Inquiry 16, pp.95-100. Oslo: Taylor \& Francis.

Naess, A. and Dregson, A. (2005). The Selected Works of Arne Naess. Dordrecht: Springer. 
Nussbaum, M.C. (1978). Aristotle’s De Motu Animalium. Princeton, N.J.: Princeton UP.

Nussbaum, M.C. (2001). The Fragility of Goodness. New York: Cambridge UP.

Plato. (1999). Euthyphro. Apology. Crito. Phaedo. Phaedrus. Cambridge MA: Harvard UP.

Plumbwood, V. (2002). The Ecological Crisis of Reason. New York: Routledge.

Roochnick, D. (2004). Retrieving the Ancients. Oxford: Blackwell.

Sandler, R. (2004). On Aristotle and the Environment. The Journal of Environmental Ethics, 26, pp. 223-24.

Serres, M. (1992). Le Contract Naturel. Paris: Flammarion.

Smith, A.D. (2003). Husserl and the Cartesian Meditations. New York: Routledge.

Spinoza, B. (2000). Ethics. Oxford: Oxford UP. 